\title{
Endourological treatment of bilateral ureteral stones in bilateral ureteral duplication with right ureterocele
}

\author{
Volkan Sen, MD; Ozgu Aydogdu, MD; Tarık Yonguc, MD; Ibrahim Halil Bozkurt, MD, FEBU; Salih Polat, MD; \\ Ismail Basmaci, MD
}

Izmir Bozyaka Training and Research Hospital, Department of Urology, Izmir, Turkey

Cite as: Can Urol Assoc J 2015;9(7-8):E51 1-3. http://dx.doi.org/10.5489/cuaj.2553 Published online July 17, 2015.

\section{Abstract}

Bilateral collecting system duplication is a very rare abnormality, including the splitting of the ureteric bud. Complete ureteral duplication with two separate openings in the urinary bladder is also extremely rare. To the best of our knowledge, we present the first case of bilateral ureteral stones in bilateral duplicated collecting system.

\section{Introduction}

Duplicated collecting system is one of the most common congenital renal tract abnormalities, with the incidence of $0.7 \%$ to $4 \% .^{1,2}$ It is characterized by incomplete fusion of lower and upper pole moieties resulting in incomplete or complete duplication of the collecting system. ${ }^{3}$ Most duplicated systems are asymptomatic and being diagnosed incidentally. Bilateral collecting system duplication is a very rare abnormality, including the splitting of the ureteric bud. ${ }^{4}$ Complete ureteral duplication with two separate openings in the urinary bladder is also extremely rare. ${ }^{3}$ To our knowledge, we report the first case of bilateral ureteral stones in bilateral duplicated collecting system: the left incomplete and the right complete ureteral duplication with two separate openings into the bladder and ureterocele formation.

\section{Case report}

A 44-year-old man presented with a 5-day history of severe bilateral flank pain. There was no operation and extracorporeal shock wave lithotripsy in history. His abdomen was unremarkable and no costovertebral angle tenderness was appreciated in physical examination. Laboratory analysis revealed as a serum creatinine $0.9 \mathrm{mg} / \mathrm{dL}$, hemoglobin $14.8 \mathrm{~g} / \mathrm{dL}$, and normal urine test. Computed tomography
(CT) scan showed bilateral distal ureteral stones: $8 \mathrm{~mm}$ in the left and about $2 \mathrm{~cm}$ in the right ureter with bilateral duplicated collecting system; the ureter draining the upper pole of right kidney was dilated (Fig. 1).

Preoperatively, we considered a diagnosis of bilateral incomplete ureteral duplication according to $\mathrm{CT}$ findings. During cystoscopy, edematous appearance was seen in the bladder trigone and bilateral ureteral orifices were seen in normal locations. In the left ureterorenoscopy, a 8-mm ureteral stone was detected at the junction of the duplicated ureters and laser lithotripsy was performed (Fig. 2). No stone was found in the right ureter during ureterorenoscopy. A bulging was detected near the right ureter and ureterocele was suspected as initial diagnosis. After transuretral resection of the bulging area, the second ureteral orifice, which is a part of complete duplicated system on the right side, became visible (Fig. 3). There were 3 stones, the largest of about $1 \mathrm{~cm}$ in diameter, in the right ureter and the system was dilated. Stones were fragmented with laser litotriptor and removed from the ureter using foreign body forceps. The postoperative period was uneventful and the patient was discharged on the postoperative day 1 .

\section{Discussion}

Duplicated collecting system is one of the most common congenital anomaly of the urinary tract. ${ }^{1,2}$ Incomplete duplication is three times more common than complete duplication. Complete ureteral duplication is more rarely observed when compared with single ureter or partial duplication. Embryologically, duplication occurs when two separate ureteric buds arise from a single Wolffian duct. Interestingly, and explaining the Weigert-Meyer rule, the future lower pole ureter separates from the Wolffian duct earlier and migrates superiorly and laterally as the urogenital sinus grows. ${ }^{5}$

The terminology surrounding duplex kidneys has been conflicting. A standardized terminology was drawn up in 1984 by the American Academy of Pediatrics (AAP), and this has been widely adopted. ${ }^{6}$ Most duplicated sys- 

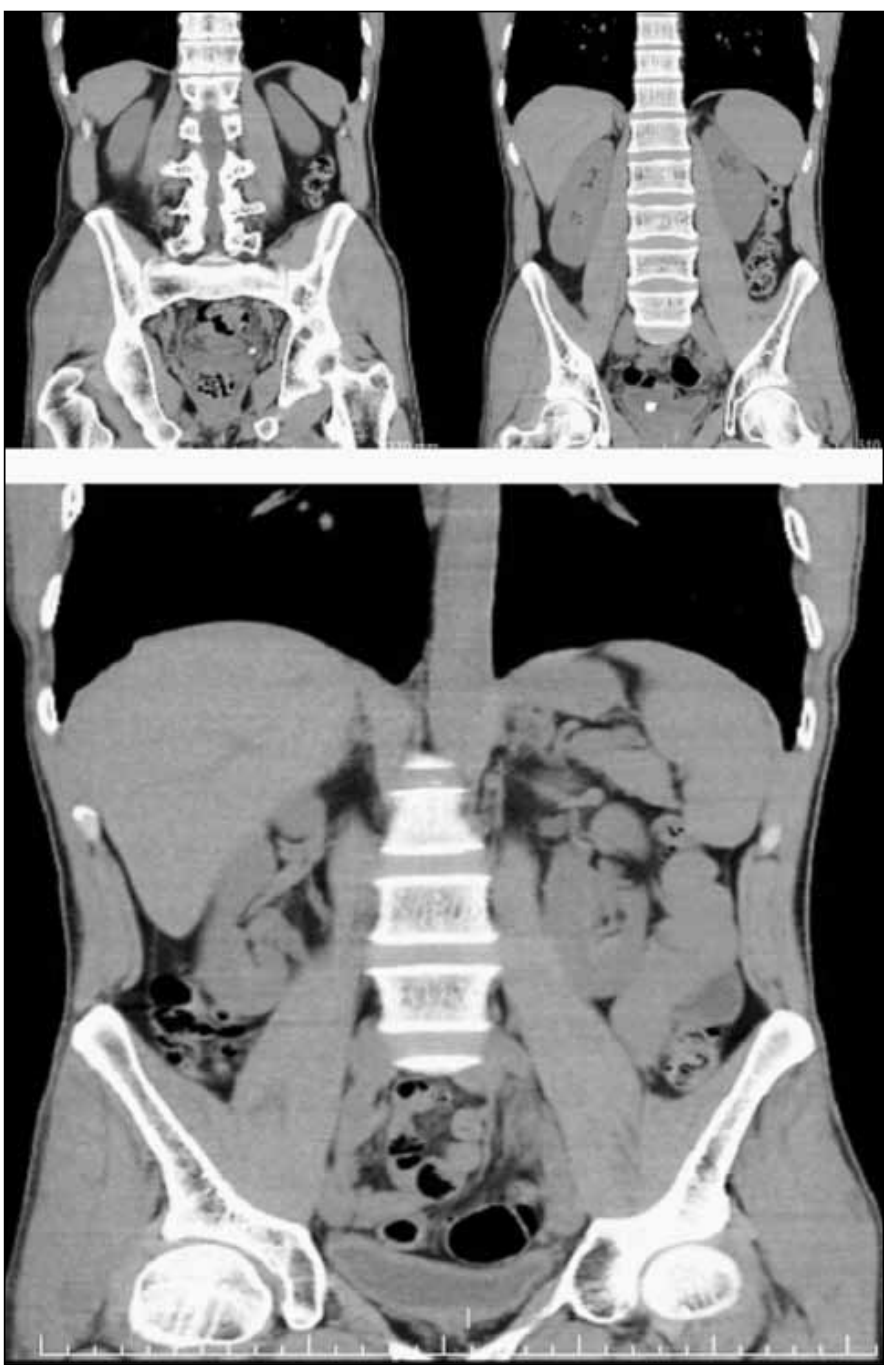

Fig. 1. Computed tomography scan of bilateral duplicated ureters.

tems are asymptomatic and being diagnosed incidentally. Presentation of duplication is variable and highly dependent on age. The most common clinical presentation is recurrent urinary tract infection in childhood. ${ }^{7}$ Therefore the duplicated collecting system could be a differential diagnosis in pediatric urinary tract infections. Vesicoureteral reflux and flank pain with the obstruction could be seen in childhood and adults. Hematuria and stone formation are other symptoms especially in adults. Complete duplication may result in an ectopic ureter implanted into the urethra and vagina causing urinary incontinence and ureterocele. ${ }^{8}$

Kidney morphology, ureter status, and renal function should be shown with imaging modalities. Intravenous urography can be used for renal function evaluation, but not sensitive for demonstrating kidney morphology and ectopic orifices. Spiral CT urography is a good choice for demonstrating the ectopic orifice and it can inform urinary tract morphology and renal function. Magnetic resonance

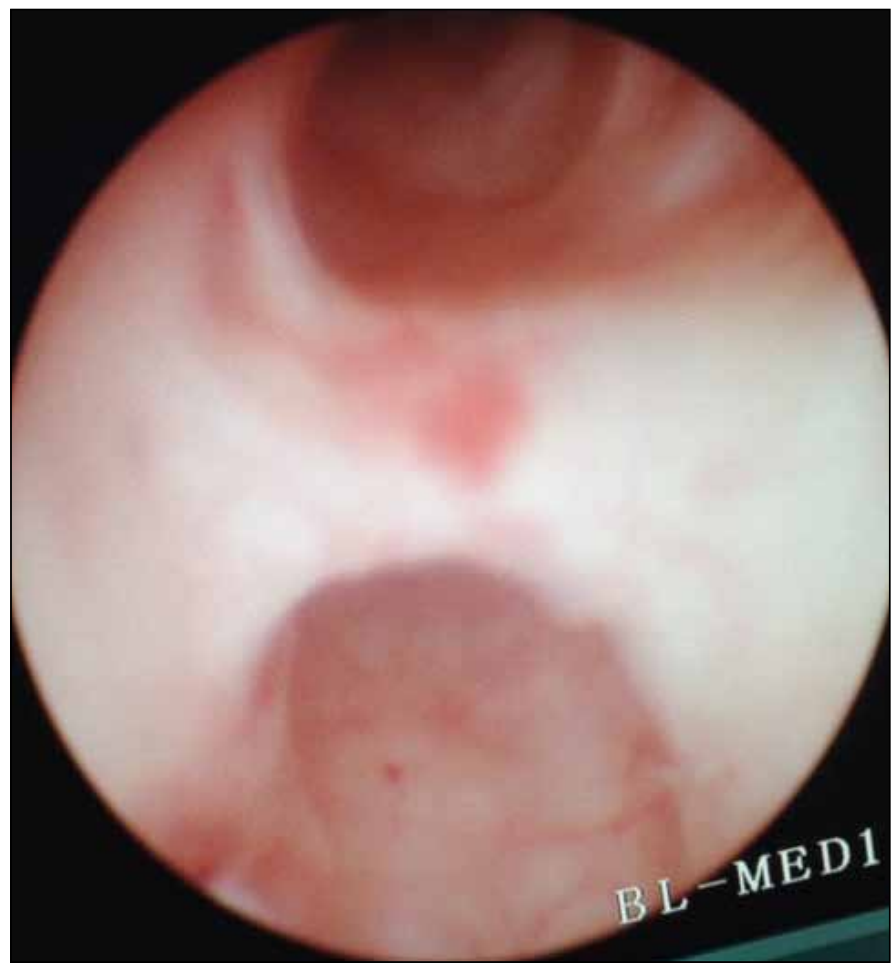

Fig. 2. The junction of the left duplicated ureters.

urography is a good alternative for evaluating urinary tract in children without the utilization of ionizing radiation. Urinary stone formation is a potential comorbidity which can be observed in patients with duplicated systems. ${ }^{3}$ There are few reports, including patients with urinary stone and duplicated systems, with coexisting ureterocele. ${ }^{1-3}$ Besides, complete ureteral duplication with two separate openings in the urinary bladder is extremely rare. To the best of our knowledge our patient presents the first case of bilateral ureteral stones

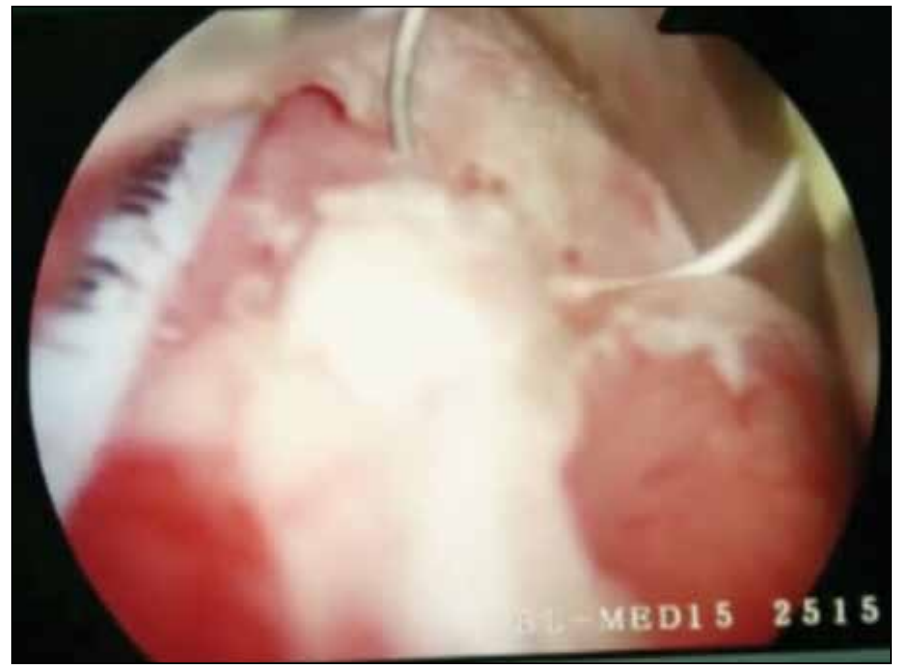

Fig. 3. After the transurethral resection, image of right complete ureteral duplication with ureterocele formation. 
in bilateral duplicated collecting system; the left incomplete and right complete ureteral duplication with two separate openings into the bladder and with ureterocele formation. ${ }^{9}$

In the recent patient, during cystoscopy we could see single ureteral opening on the right side and there was no ureteral stone during ureteroscopy. However we wanted to be sure there was another ureteral opening and decided to resect the bulging area next to the right visible ureteral orifice. Finally we found the second right ureteral orifice of the right complete duplex system and performed ureterorenoscopy and laser lithotripsy. Although we successfully removed stones without complications on both sides, right ureteral stones might have been left behind had we not decided to resect the urinary bladder tissue.

\section{Conclusion}

Since the success and complication rates may negatively affect patients with urinary stones and coexisting anomalies, clinicians should be alert for potential rare anomalies of the urinary system before surgical procedures. Preoperative careful radiologic evaluation of patients with rare coexisting anomalies of the urinary system is crucial before deciding on other surgical moves intra-operatively.

Competing interests: The authors all declare no competing financial or personal interests.
This paper has been peer-reviewed.

\section{References}

1. Kawahara $\mathrm{T}$, Ito $\mathrm{H}$, Terao $\mathrm{H}$, et al. Ureteroscopy assisted retrograde nephrostomy (UARN) for an incomplete double ureter. Urol Res 2012;40:781-2. http://dx.doi.org/10.1007/s00240-012-0486-y

2. Inamoto K, Tanaka S, Takemura K, et al. Duplication of the renal pelvis and ureter: Associated anomaliesand pathological conditions. Radiat Med 1983;1:55-64.

3. Karakose A, Aydogdu 0, Atesci YZ. Unilateral complete ureteral duplication with ureteral stone: A rare entity. Can Urol Assoc J. 2013;7:E511-2. htrp://dx.doi.org/10.5489/cuaj.410

4. Scantling D, Ross C, Altman H. A 52-year-old male with bilaterally duplicated collecting systems with obstructing ureteral stones: A case report. Curr Urol 2013;7:104-6. http://dx.doi.org/10.1159/000356257

5. Mackie GG, Stephens FD. Duplex kidneys: A correlation of renal dysplasia with position of the ureteral orifice. J Urol 1975;14:274-80.

6. Glassberg Kl, Braren V, Duckett JW et al. Suggested terminology for duplex systems, ectopic ureters and ureteroceles. J Urol 1984;132:1153-4.

7. Siomou E, Papadopoulou F, Kollios KD, et al. Duplex collecting system diagnosed during the first 6 years of life after a first urinary tract infection: A study of 63 children. J Urol 2006;175:678-81. http:// dx.doi.org/10.1016/S0022-5347(05)00184-9

8. Fernbach SK, Feinstein KA, Spencer K, et al. Ureteral duplication and its complications. Radiographics 1997;17:109-27. http://dx.doi.org/10.1148/radiographics.17.1.9017803

9. Ma R, Wu RD, Liu W, et al. A new classification of duplex kidney based on morphology and management. Chin Med J (Engl) 2013;126:615-9.

Correspondence: Dr. Volkan Sen, Izmir Bozyaka Training and Research Hospital, Department of Urology, Izmir, Turkey; sen_volkan@yahoo.com 